\title{
ANALISIS RANTAI NILAI UBI KAYU (Manihot esculeta crantz) DI KABUPATEN PATI
}

\author{
Donny Puja Puspito'), Kusnandar ${ }^{1)}$, Nuning Setyowati ${ }^{1)}$ \\ ${ }^{1)}$ Program Studi Agribisnis, Fakultas Pertanian, Universitas Sebelas Maret \\ Email: donny.pp@student.uns.ac.id
}

\begin{abstract}
This study aimed to analyze the value chain mapping, governance, improvement of value chain and marketing margins cassava in Pati regency. The basic method used descriptive analytical research. The method of determining the location of the research method and the purposive sampling method is done by snowball sampling with 18 respondents. The results showed there are three models of the value chain by five actors, namely farmers, penebas, grinders, realtor, and collectors flour. Valueadded activities conducted on cassava farmers, grinders and collectors. While penebas and brokers act as a liaison between value chain actors. Governance cassava value chain is analyzed through three approaches namely coordination structures, rules and regulations, and provider of information and services. The increase in the value chain are identified in several aspects of increase of processes, products, and functions. Enhanced functions effectively needs to be done because it will produce a positive impact on the actors of the value chain. Grinder has a marketing margin of RP $3300 / \mathrm{kg}$, meaning that most large margin than other players because it has many activities ranging from wet to cassava starch that have added value. While the perpetrators of broker only has a margin of RP $20 / \mathrm{kg}$ for his activities only as an intermediary without any added value from the starch itself.
\end{abstract}

Keywords: Cassava, Governance, Mapping the Value Chain, Marketing Margin, Upgrading Value Chain,

\section{PENDAHULUAN}

Sektor pertanian berkaitan erat dengan sektor industri karena dengan adanya perkembangan pada sektor pertanian, maka akan mendorong sektor industri agar semakin maju. Keterkaitan antara sektor pertanian dengan sektor industri perlu di arahkan untuk mengembangkan sektor hilir dan memperkuat sektor hulu, dengan kata lain suatu kondisi ekonomi yang seimbang antara bidang industri yang didukung penuh oleh pertanian. Sektor industri yang dimaksud dalam hal ini terutama pada sektor industri pengolah hasil pertanian.

Salah satu industri pengolah hasil pertanian yang saat ini sedang dikembangkan merupakan penyerap hasil pertanian seperti umbi-umbian sebagai bahan pangan altenatif selain beras. Ubi kayu adalah tanaman jenis umbi-umbian yang menjadi salah satu fokus pengembangan komoditas pertanian, karena mempunyai beragam produk turunan yang sangat prospektif dan berkelanjutan. Manfaat ubi kayu dalam fokus pengembangan komoditas dibagi menjadi bahan makanan pokok lokal, produk industri pertanian, dan bahan baku industri sehingga sangat berpotensi untuk dikembangkan.
Produksi ubi kayu di Jawa Tengah tidak lepas dari peran daerah atau kabupaten penyangga produksi ubi kayu salah satunya Kabupaten Pati. Ubi kayu merupakan pangan alternatif potensial di Kabupaten Pati yang bisa meningkatkan pendapatan petani. Produksi Ubi kayu segar di Kabupaten Pati sebagian besar diolah menjadi tepung tapioka, hal ini sekaligus menunjukkan adanya keterkaitan yang kuat antara sektor pertanian sampai ke industri pengolahan yang dikelola oleh masyarakat Kabupaten Pati. Keterkaitan yang di maksud adalah hubungan sosial yang terjadi antara petani ubi kayu dan pelaku lain yang terlibat dalam tatanan rantai nilai. Menurut Kaplinsky dan Morris (2001) rantai nilai terdiri dari berbagai pelaku (produsen utama, pengolah, pedagang, penyedia jasa) dapat terbentuk jika semua pelaku dalam rantai tersebut bekerja sedemikian rupa sehingga memaksimalkan terbentuknya nilai sepanjang rantai tersebut.

Permasalahan utama yang dihadapi petani ubi kayu di Kabupaten Pati dalam rantai nilai antara lain adalah ketersediaan pupuk yang kurang memadai, keadaan tanah yang semakin melemah, kurangnya inovasi teknologi mengenai budidaya ubi kayu, hubungan antara pelaku rantai nilai yang belum terintegrasi 
dengan baik, dan tingkat harga ubi kayu yang relatif yang tidak stabil. Segala bentuk perbaikan dalam rantai nilai sangat dibutuhkan guna untuk mencapai keseimbangan manfaat yang diterima oleh setiap pelakunya. Adapun tujuan penelitian ini antara lain menganalisis pemetaan rantai nilai, tata kelola, dan opsi peningkatan rantai nilai ubi kayu di Kabupaten Pati.

\section{METODE PENELITIAN}

\section{Metode Dasar Penelitian}

Penelitian ini menggunakan metode dasar deskripsi. Metode deskripsi ini bertujuan untuk menggambarkan secara tepat sifat-sifat suatu individu, keadaan, gejala, atau kelompok tertentu, atau untuk menentukan frekuensi atau penyebaran suatu gejala (Silalahi, 2012). Teknik penelitian yang digunakan adalah metode survey, yaitu cara pengambilan data dari sejumlah unit dan individu dalam jangka waktu yang bersamaan dalam jumlah besar dan luas. Survey berusaha mengungkapkan jawaban melalui pertanyaan apa, bagaimana, berapa, bukan pertanyaan mengapa dengan menggunakan alat bantu kuesioner (Kountur, 2003).

\section{Waktu dan Lokasi Penelitian}

Pemilihan lokasi penelitian dilakukan secara sengaja atau purposive, yaitu penentuan daerah sampel yang diambil secara sengaja berdasarkan pertimbangan tertentu. Penelitian ini sengaja dilaksanakan di Kabupaten Pati dengan berbagai pertimbangan bahwa Kabupaten Pati merupakan salah satu sentra pertanian ubi kayu yang berada pada posisi ke dua setelah Kabupaten Wonogiri di Provinsi Jawa Tengah.

\section{Metode Penentuan Sampel}

Sampel dalam penelitian rantai nilai komoditas ubi kayu ditentukan dengan metode Snowball Sampling dengan Bapak Ngasbi (Ketua Kelompok Tani di Desa Tlogosari, Kecamatan Tlogowungu, Kabupaten Pati) sebagai Key Informan pada petani ubi kayu untuk merunut alur aliran produk ubi kayu dari hulu sampai hilir. Menurut Silalahi (2012), Prosedur pemililhan sampel bola salju dilakukan secara bertahap. Pertama-tama, diidentifikasi orang yang dianggap dapat memberi informasi untuk diwawancara. Kemudian orang ini dijadikan sebagai informan untuk mengidentifikasi orang lain sebagai sampel yang dapat memberi informasi dan orang ini juga dijadikan informan untuk mengidentifikasi orang lain sebagai sampel yang dianggap dapat memberi informasi. Demikian proses ini berlangsung hingga terpenuhi jumlah anggota sampel yang dikehendaki. Berdasarkan metode Snowball Sampling didapatkan 18 responden dengan rincian 8 petani, 3 penebas, 2 penggiling, 2 makelar dan 3 Pengepul.

\section{Metode Analisis Data}

Analisis rantai nilai mengacu pada serangkaian kegiatan yang diperlukan untuk menghadirkan suatu produk (atau jasa) dimulai dari tahap konseptual, dilanjutkan dengan beberapa tahap produksi, hingga pengiriman ke konsumen akhir dan pemusnahan setelah penggunaaanya (Kaplinsky 1999; Kaplinsky dan Morris 2001).

\section{Pemetaan Rantai Nilai}

Mengidentifikasi dan memetakan proses inti, para pelaku yang terlibat dalam rantai nilai. Peta yang dihasilkan menggambarkan para pelaku secara umum. Peta ini dapat dikembangkan lebih lanjut dengan merinci proses inti menjadi kegiatan spesifik yang dijalankan oleh pelaku yang berbeda-beda sebagaimana telah teridentifikasi. Berdasarkan metode Snowball Sampling didapatkan 18 responden dengan rincian 8 petani, 3 penebas, 2 penggiling, 2 makelar dan 3 Pengepul.

2. Tata Kelola

Tata kelola merupakan konsep yang pada dasarnya memastikan bahwa interaksi antara para peserta di dalam rantai nilai telah terorganisir, dan bukan hanya sekedar terjadi secara acak. Pendekatan terbaik dalam analisis tata kelola rantai nilai dilakukan dengan cara memilah 3 dimensi : Struktur Koordinasi, Peraturan dan Regulasi, Penyedia Informasi dan Layanan. Manajemen rantai pasok adalah keterpaduan antara perencanaan, koordinasi dan kendali seluruh proses dan aktivitas bisnis dalam rantai pasok untuk menghantarkan nilai superior dari konsumen dengan biaya termurah kepada pelanggan. Rantai pasok lebih ditekankan pada seri aliran bahan dan informasi, sedangkan manajemen rantai pasok menekankan pada upaya memadukan kumpulan rantai pasok 
(Van der Vorst, 2006).

3. Peningkatan Rantai Nilai

Alat analisis ini dilakukan untuk mengidentifikasi berbagai peningkatan (upgrading) yang mungkin dilakukan. Ada berbagai aspek dalam peningkatan yaitu peningkatan proses, produk, dan fungsi. Peningkatan proses (Upgrading Process) mengacu pada efisiensi produksi. Peningkatan produk (Product Upgrading) pada diperkenalkannya produk-produk baru, atau penyempurnaan produk lama. Peningkatan fungsi (Functional Upgrading) mengacu pada pertanyaan dasar tentang kegiatan mana yang harus mendapat konsentrasi penuh dari para pelaku dalam rantai nilai.

\section{HASIL DAN PEMBAHASAN}

\section{Pemetaan Rantai Nilai}

a. Proses Inti Rantai Nilai

Alat ini bertujuan mengidentifikasi proses apa saja yang terjadi mulai dari input/sarana produksi untuk bahan baku hingga konsumen akhir produk. Proses tersebut disesuaikan dengan karakteristik rantai yang dipetakan. Ubi kayu merupakan bahan dasar industri tepung tapioka. Terdapat 5 proses inti dalam rantai nilai ubi kayu yaitu penyediaan input, penanaman, produksi, pemasaran, konsumen. b. Pelaku dan Kegiaatn Rantai Nilai

Pada rantai nilai ubi kayu di Kabupaten Pati terdapat 5 (lima) pelaku rantai nilai dan terdapat 3 model rantai nilai. Pemetaan rantai nilai dapat dikatakan wajar karena setiap pelaku sudah memiliki fungsi dan peran masingmasing. Model Rantai Nilai dapat dilihat pada gambar 1. Setiap pelaku mempunyai fungsi dan peran yang digambarkan dalam setiap kegiatan pertambahan nilai ubi kayu terutama pada petani, penggiling, dan pengepul tepung. Penggiling memiliki kegiatan paling dominan diantara pelaku rantai nilai lainya karena hampir setiap hari proses produksi berjalan mulai dari datangnya ubi kayu basah sampai menjadi tepung tapioka setengah jadi. Dalam segi penyerapan tenaga kerja juga penggiling menyerap banyak tenaga kerja setiap harinya seperti tenaga bongkar truk, tenaga kupas, tenaga pencuci, tenaga penggiling dan tenaga penjemur. Sedangkan penebas dan makelar merupakan pelaku yang tidak melakukan pertambahan nilai melainkan berperan sebagai perantara. Kegiatan Rantai Nilai dapat dilihat pada tabel 1

Peta Rantai Nilai 1

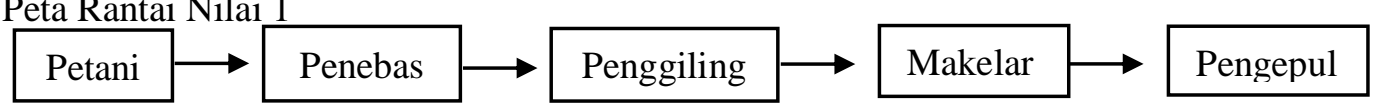

Peta Rantai Nilai 2

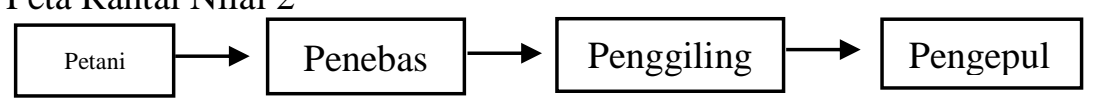

Peta Rantai Nilai 3

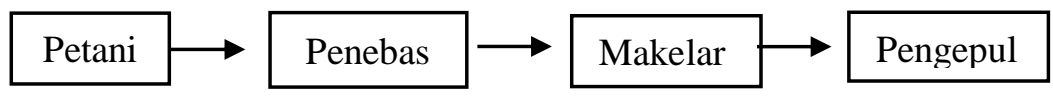

Gambar 1. Peta rantai nilai ubi kayu di Kabupaten Pati. 
Tabel 1. Kegiatan pelaku dalam rantai nilai ubi kayu di Kabupaten Pati

\begin{tabular}{ll}
\hline \multicolumn{1}{c}{ Pelaku Rantai Nilai } & \multicolumn{1}{c}{ Kegiatan } \\
\hline Petani Ubi Kayu & Pengolahan Lahan, Penanaman, Pemeliharaan, Panen, Penjualan \\
Penebas & Penafsiran Lahan, Negosiasi harga dengan petani, Panen, Negosiasi \\
& Harga dengan Penggiling, Pengangkutan, Penimbangan \\
Penggiling & $\begin{array}{l}\text { Pembelian ubi kayu, Penimbangan, Pengupasan, Pencucian, } \\
\text { Penggilingan, Pengendapan, Penjemuran, Penjualan }\end{array}$ \\
Makelar & Pembelian, penjualan \\
Pengepul Tepung & $\begin{array}{l}\text { Pembelian, penimbangan, penggilingan, pengemasan,pengangkutan, } \\
\text { penjualan }\end{array}$ \\
\hline Sumber :
\end{tabular}

Sumber : Data primer tahun 2016.

c. Aliran Rantai Nilai

Berdasarkan gambar 2 diatas mennunjukkan bahwa aliran produk ubi kayu dimulai dari petani kemudian dijual kepada penebas atau langsung kepada penggiilng ubi kayu menggunakan kendaraan truk. Setelah ubi kayu diolah penggiling menjadi tepung tapioka setengah jadi kemudian akan di datangi oleh makelar tepung yang siap menjual kepada pengepul tepung. Penggiling juga dapat menjual secara langsung kepada pengepul dengan catatan sudah mempunyai hubungan kerjsama yang baik.

Aliran finansial mengalir dari pengepul tepung, makelar tepung, penggiling ubi kayu, penebas, dan petani. Sistem pembayaran pengepul tepung, makelar tepung, dan penebas secara umum dengan sistem tunda paling lama 1 minggu dengan cara transfer. Sedangkan pada petani menghendaki pembayaran secara langsung sesuai dengan jumlah ubi kayu yang dibeli.
Aliran informasi terjadi pada semua anggota rantai nilai ubi kayu. Aliran informasi meliputi informasi tentang harga dan pasar. Informasi tentang harga hanya terjadi antara beberapa tingkat pelaku rantai nilai saja misalkan petani dengan penebas dan penggiling ubi kayu, penggiling ubi kayu dengan makelar tepung dan pengepul tepung. Aliran informasi mengenai pasar terjadi pada semua anggota rantai nilai, artinya petani mengetahui bahwa ubi kayu akan dipasarkan di daerah Kecamatan Margoyoso untuk diolah menjadi tepung tapioka. Jika seorang petani ubi kayu ingin menjual ubi kayu maka informasi tersebut akan tersebar sehingga para penebas akan berdatangan untuk membeli ubi kayu petani tersebut. Hal ini juga terjadi ketika penggiling memerlukan bahan baku makan akan memberikan informasi kepada beberapa penebas yang dipercaya untuk mencarikan ubi kayu. 


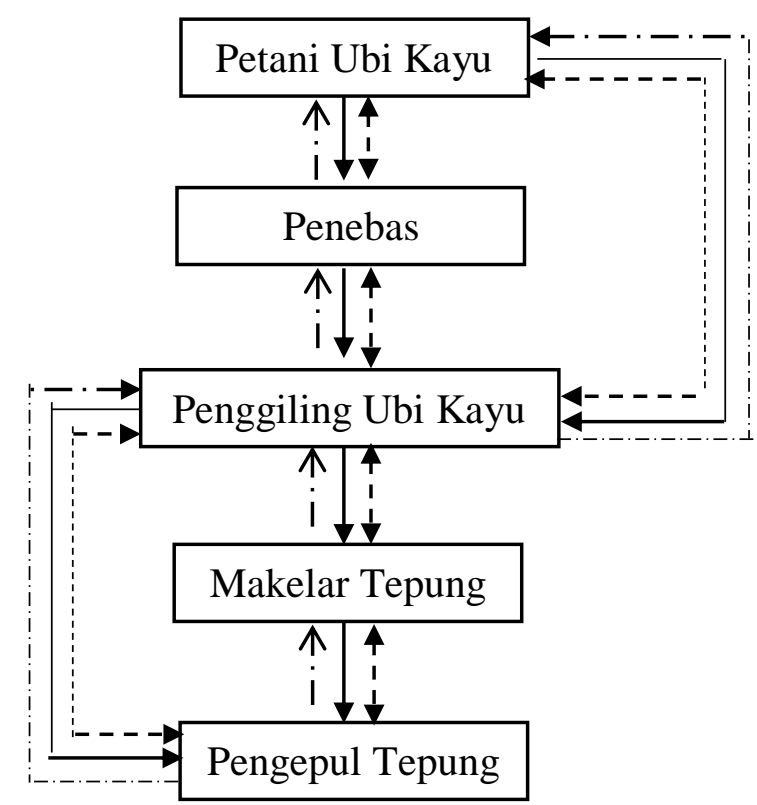

Keterangan :

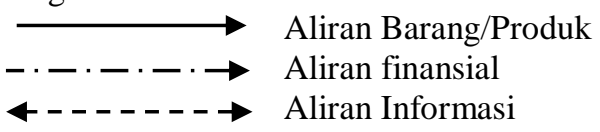

Gambar 2. Aliran rantai nilai ubi kayu di Kabupaten Pati.

Pemetaan Marjin Pemasaran pada Pelaku Rantai Nilai

Nilai marjin keuntungan pada masing-masing pola rantai nilai ubi kayu di Kabupaten Pati dapat dilihat pada tabel 3. Penggiling mempunyai marjin yaitu $\mathrm{Rp} 3300 / \mathrm{Kg}$, artinya marjin yang paling besar daripada pelaku yang lain karena memang mempunyai aktivitas yang banyak mulai dari ubi kayu basah sampai tepung tapioka sehingga mengalami pertambahan nilai. Sedangkan pada pelaku makelar hanya mempunyai marjin sebesar $\mathrm{Rp} 20 / \mathrm{Kg}$ karena aktivitasnya hanya sebagai perantara tanpa ada pertambahan nilai dari tepung tapioka itu sendiri. Perbedaan

harga di masing-masing lembaga pemasaran sangat bervariasi tergantung besar kecilnya keuntungan yang diambil oleh masing-masing lembaga pemasaran (Soekartawi, 1993).

Model rantai nilai juga digunakan untuk memahami interaksi yang terjadi antar aktor, yaitu meningkatkan efisiensi dengan tetap meningkatkan nilai tambah dan meningkatkan daya tawar antar aktor yang terlibat untuk memberikan kontribusi terhadap nilai tambah suatu produk (Roduner, 2007). Menurut
Kaplinsky dan Morris, 2001, analisis rantai nilai dapat memainkan peran utama dalam mengidentifikasi distribusi manfaat bagi para pelaku dalam rantai nilai.

\section{Tata Kelola}

Pendekatan terbaik dalam analisis tata kelola rantai nilai dilakukan dengan cara memilah 3 dimensi : Sistem Koordinasi, Peraturan dan Regulasi, Penyedia Informasi dan Layanan.

a. Sistem Koordinasi

Rantai nilai ubi kayu di Kabupaten Pati belum seluruhnya melaksanakan koordinasi dengan baik. Petani sebagai produsen utama yang membudidayakan ubi kayu. Penebas mengorganisir hasil panen dari beberapa petani untuk dikirimkan ke penggiling secara kontinu. Penggiling menerima ubi kayu basah dari petani dan penebas kemudian melakukan proses produksi. Makelar berperan menghubungkan beberapa penggiling ke pengepul tepung. Pengepul menggiling kembali tepung setengah jadi kemudian dikemas dalam bentuk karung $50 \mathrm{~kg}$.

b. Peraturan dan Regulasi

Hasil penelitian menunjukkan bahwa tidak ada peraturan tertulis baik dari penebas kepada petani, penggiling 
kepada penebas dan petani, makelar kepada penggiling, dan pengepul kepada makelar. Kesepakatan kerjasama dilakukan menggunakan prinsip kepercayaan dengan memegang komitmen untuk saling jujur, rasa saling membutuhkan dan ketergantungan satu sama lain.

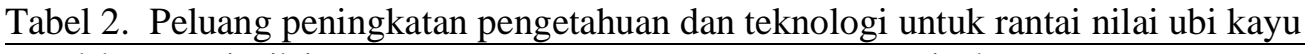

\begin{tabular}{|c|c|c|c|}
\hline \multirow[t]{2}{*}{ Pelaku Rantai Nilai } & \multicolumn{3}{|c|}{ Peningkatan } \\
\hline & Produk & Proses & Fungsi \\
\hline Petani & $\begin{array}{r}\text { - Varietas } \\
\text { tanaman }\end{array}$ & $\begin{array}{l}\text { - Pengolahan lahan } \\
\text { - Pengaturan jarak tanam }\end{array}$ & \\
\hline Penebas & & & - Penguatan jaringan kerjasama \\
\hline Penggiling Ubi Kayu & & - Kebersihan tepung & $\begin{array}{l}\text { - Pinjaman modal } \\
\text { - Pengolahan limbah } \\
\text { - Pembentukan kelompok usaha }\end{array}$ \\
\hline Makelar Tepung & & & - Penguatan jaringan kerjasama \\
\hline Pengepul Tepung & & - Manajemen mutu & - Kesehatan karyawan \\
\hline
\end{tabular}

Sumber : Data primer tahun 2016.

Tabel 3. Marjin pemasaran pada setiap pelaku rantai nilai ubi kayu per Kg di Kabupaten Pati

\begin{tabular}{lrrrrrr}
\hline \multirow{2}{*}{ Pelaku } & \multicolumn{2}{c}{ Rantai Nilai 1 } & \multicolumn{2}{c}{ Rantai Nilai 2 } & \multicolumn{2}{c}{ Rantai Nilai 3 } \\
\cline { 2 - 7 } & $\begin{array}{c}\text { Harga jual } \\
\mathrm{Rp} / \mathrm{Kg}\end{array}$ & $\begin{array}{c}\text { Marjin } \\
\text { Pemasaran } \\
\mathrm{Rp} / \mathrm{Kg}\end{array}$ & $\begin{array}{c}\text { Harga jual } \\
\mathrm{Rp} / \mathrm{Kg}\end{array}$ & $\begin{array}{c}\text { Marjin } \\
\text { Pemasaran } \\
\mathrm{Rp} / \mathrm{Kg}\end{array}$ & $\begin{array}{c}\text { Harga jual } \\
\mathrm{Rp} / \mathrm{Kg}\end{array}$ & $\begin{array}{c}\text { Marjin } \\
\text { Pemasaran } \\
\mathrm{Rp} / \mathrm{Kg}\end{array}$ \\
\hline Petani & 1200 & - & 1200 & - & 1800 & - \\
Penebas & 1800 & 600 & 1800 & 600 & - & - \\
Penggiling & 5100 & 3300 & 5100 & 3300 & 5100 & 3300 \\
Makelar & 5120 & 20 & - & - & 5120 & 20 \\
Pengepul & 6100 & 980 & 6100 & 1000 & 6100 & 980 \\
Total & & 4900 & & 4900 & & 4300 \\
\hline
\end{tabular}

Sumber Data : Data primer tahun 2016.

c. Penyedia Informasi dan Layanan Penyedia informasi bagi petani ubi kayu berasal dari kantor penyuluhan pertanian Kecamatan Tlogowungu dan saling berbagi informasi antara petani mengenai budidaya ubi kayu, harga, dan pasar. Dukungan yang ada bagi petani hanya berupa informasi saja sedangkan dukungan berupa dana dan bantuan fisik seperti pupuk, obat pertanian sepenuhnya menjadi tanggungan petani itu sendiri. Penggiling dan pengepul tepung mendapat bantuan berupa perijinan usaha dari Dinas Perindustrian dan Perdagangan Kabupaten Pati, pihak bank juga menawarkan bantuan pinjaman modal untuk memperlancar dan memperbesar usaha mereka, serta jaringan pasar luas yang didapatkan dengan hubungan yang baik pada tingkat pelaku yang sama. Sedangkan penebas dan makelar tepung hanya mendapat informasi jaringan pasar mereka sendiri, selain itu penebas juga mendapat bantuan pinjaman modal dari bank.

Struktur koordinasi terus-menerus berkembang untuk memungkinkan pelaku memenuhi persyaratan kompetitif dalam pasar-antara dan pasar-akhir. Menurut (Gereffi, Humphrey et al 2003), mengklasifikasikan rantai nilai secara global menjadi 5 yaitu pasar, modular, relasional, hubungan pasti, dan hirarki. Struktur koordinasi ini berkisar mulai dari struktur perdagangan berbasis pasar dengan koordinasi yang amat longgar hingga produksi terintegrasi vertikal yang sangat terkoordinir. Keadaan dilapang menunjukkan bahwa klasifikasi rantai nilai pasar terjadi pada petani, penebas, penggiling, makelar dan pengepul karena dasar koordinasi antara pelaku adalah harga.

3. Menganalisis Peningkatan Rantai Nilai

Analisis rantai nilai dapat digunakan untuk mempertimbangkan besarnya kekuasaan berbagai pelaku serta berbagai nilai tambah di sepanjang suatu rantai. 
Dengan mengendalikan lebih banyak sambungan dalam suatu rantai nilai, atau memiliki suatu sistem penambah nilai dengan berbagai cara, memberikan produsen pengaruh lebih kuat terkadang disebut kendali lebih besar atas sang pembeli. Hal ini diistilahkan "upgrading atau peningkatan," yakni menambah nilai pada suatu produk dan menggeser kekuasaan dari pembeli ke penjual (ADB, 2005).

Peningkatan rantai nilai diidentifikasi dalam beberapa aspek peningkatan yaitu proses, produk, dan fungsi. Peningkatan rantai nilai dapat dilihat pada tabel 2 . Peningkatan rantai nilai diidentifikasi dalam beberapa aspek peningkatan yaitu proses, produk, dan fungsi. Kinerja keseluruhan rantai nilai dapat ditingkatkan melalui penentuan tingkatan dalam rantai nilai yang paling efektif. Peningkatan fungsi perlu dilakukan secara efektif karena akan menghasilkan dampak positif bagi pelaku-pelaku rantai nilai.

\section{KESIMPULAN}

Berdasarkan hasil analisis rantai nilai komoditas ubi kayu di Kabupaten Pati dibagi menjadi 3 aspek yaitu pemetaan rantai nilai, tata kelola, dan peningkatan upaya rantai nilai. Pemetaan Rantai Nilai pada rantai nilai ubi kayu di Kabupaten Pati terdapat 3 model rantai nilai dan 5 (lima) pelaku rantai nilai yaitu petani, penebas, penggiling, makelar, dan pengepul. setiap pelaku mempunyai fungsi dan peran yang digambarkan dalam setiap kegiatan pertambahan nilai ubi kayu terutama pada petani, penggiling, dan pengepul tepung.

Tata kelola dibagi menjadi 3 dimensi yaitu sistem koordinasi, peraturan dan regulasi, penyedia informasi dan layanan. Sistem koordinasi terjadi atas dasar harga yang berlaku. Tidak ada peraturan dan regulasi tertulis pada setiap pelaku karena kesepakatan kerjasama dilakukan menggunakan prinsip kepercayaan dengan memegang komitmen untuk saling jujur, rasa saling membutuhkan dan ketergantungan satu sama lain. Jenis informasi dan layanan yang ada mengenai budidaya ubi kayu, jaringan pasar, pinjaman modal, dan perijinan usaha. Sedangkan untuk penyedia informasi dan layanan adalah stakeholder, jaringan sesama tingkat pelaku, dan bank.
Peningkatan rantai nilai diidentifikasi dalam beberapa aspek peningkatan yaitu proses, produk, dan fungsi. Kinerja keseluruhan rantai nilai dapat ditingkatkan melalui penentuan tingkatan dalam rantai nilai yang paling efektif. Peningkatan fungsi perlu dilakukan secara efektif karena akan menghasilkan dampak positif bagi pelakupelaku rantai nilai.

\section{DAFTAR PUSTAKA}

ACIAR. 2012. Membuat rantai nilai lebih berpihak pada kaum miskin. buku pegangan bagi praktisi analisis rantai nilai. Australian Government. Australian Centre for International Agricultural Research (ACIAR).

ABD. 2005. Synthesis study on options for smallholder commercialization in zambia: outgrower case sudy - cotton. Lusaka, Zambia, Prepared for The Government of Zambia and The World Bank by Agro Business Development A/S, Denmark.

Gereffi, G., J. Humphrey, et al. 2003. The governance of global value chains: an analytical framework.

Kaplinsky, Raphael. and Morris, Mike. 2001. A handbook for value chain research. Brighton, United Kingdom, Institute of Development Studies, University of Sussex.

Kotler, Philip. 1992. Manajemen Pemasaran: Analisis, Perencanaan, dan Pengendalian. Erlangga. Jakarta.

Kountur, Ronny. 2003. Metode Penelitian Untuk Skripsi Dan Tesis. CV Taruna Grafica. Jakarta.

Roduner, Daniel, 2007. "Donor interventions in value chain development", Swiss Agency for Development and Cooperation (SDC) Switzerland.

Silalahi. 2012. Metode Penelitian Sosial Ekonomi. Penerbit Erlangga. Jakarta.

Soekartawi. 1993. Prinsip Dasar Ekonomi Pertanian (Teori dan Aplikasi). Raja Grafindo Persada. Jakarta.

Sudiyono, Armand, 2002. Pemasaran Pertanian. UMM Press. Malang.

Van der Vorst, JGAJ. 2006. Performance measurement in agri-food supply chain 
Analisis Rantai Nilai Ubi Kayu ... Puspito et al.

networks. Netherland : Logistics and

University.

Operations Research Group, Wageningen 